\title{
Single-Mode Rib Waveguides Fabricated by Means of Sol-Gel Method
}

\author{
P. Karasiński*, C. TyszkieWicz And R. Rogoziński \\ Department of Optoelectronics, Silesian University of Technology, Krzywoustego 2, 44-100 Gliwice, Poland \\ Rib waveguides were fabricated with the use of selective, wet chemical etching of two-component waveguide \\ films $\mathrm{SiO}_{2}: \mathrm{TiO}_{2}$ which were obtained using sol-gel method. Photoresist was applied as a mask in the process. \\ The etching of the films $\mathrm{SiO}_{2}: \mathrm{TiO}_{2}$ was carried out in water solution of ammonia fluoride. The paper presents the \\ results of theoretical analysis as well as the power distributions in the fabricated strip waveguides.
}

PACS numbers: 42.82.Et, 81.20.Fw, 07.07.Df

\section{Introduction}

The systems of integrated optics can be produced with the application of: ion exchange in glass [1,2], chemical vapor deposition (CVD) [3] or sol-gel technology [4-11]. The sol-gel technology has a big advantage as compared to others since it does not require expensive technological equipment and it can provide various dielectric materials of controlled structures for optoelectronics. Through an appropriate selection of components we can obtain dielectric films of different refractive indexes. In view of fabrication potential of films having significantly different refractive indexes, a two-component system $\mathrm{SiO}_{2}: \mathrm{TiO}_{2}$ is very attractive. Refractive indexes of such films can be formed within the range from $n=1.2$ (porous silica) to $n=2.3$ (dense titania). Porous silica can be applied for the production of sensitive layers where it serves as a matrix binding the indicator [8]. Films of high refractive indexes are particularly attractive for the technology of planar evanescent wave sensors [8]. In some sensor systems slab waveguides can be used $[5,6,10,11]$. However, in many other applications such as planar sensors in the system of the Mach-Zehnder interferometer or in the system of the Young interferometer, strip waveguides are required.

The present paper demonstrates the application of the method of chemical selective etching of silica-titania $\left(\mathrm{SiO}_{2}: \mathrm{TiO}_{2}\right)$ films for the fabrication of channel rib waveguides. The waveguide films $\mathrm{SiO}_{2}: \mathrm{TiO}_{2}$ were produced using sol-gel method. The work demonstrates the results of theoretical analysis as well as power distribution in the fabricated rib waveguides.

\section{Technology}

\subsection{Waveguide films}

The silica-titania waveguide films were produced using the precursors: tetraethyl orthosilicate (TEOS) for silica

* corresponding author; e-mail: pawel.karasinski@polsl.pl and tetraethyl orthotitanate (TET) for titania. The gel formation procedure was carried out in two stages. In the first stage the hydrolysis of TEOS and TET was carried out separately. Then partially hydrolyzed TET solution was added to partially hydrolyzed TEOS solution and the sol formation process was carried on. The solutions were mixed in proportions ensuring that the molar ratio $\mathrm{Si}: \mathrm{Ti}$ is 1:1. Ethyl alcohol was used as homogenizing agent and hydrochloric acid was applied as catalyst. waveguide films were coated on BK7 glass substrates $\left(76 \times 26 \times 1 \mathrm{~mm}^{3}\right)$ using dip-coating method. The fabricated structures were annealed for $1 \mathrm{~h}$ at temperature $500{ }^{\circ} \mathrm{C}$. The obtained waveguide films $\mathrm{SiO}_{2}: \mathrm{TiO}_{2}$ were characterized by low attenuation (below $0.5 \mathrm{~dB} / \mathrm{cm}$ ) [12]. The refractive index of waveguide films which were applied for the fabrication of rib waveguides was $n_{1}=1.793$.

\subsection{RIB waveguides}

The diagram of rib waveguide is presented in Fig. 1. The rib waveguides were fabricated as follows. The waveguide films formed in the sol-gel process were coated with photoresist. In the studies, the photoresist ShipleyMicroposit S1813SP15 was applied. Then the structures were subjected to UV radiation through a photomask designed for this purpose. The development of photoresist was followed by the selective uncovering of $\mathrm{SiO}_{2}: \mathrm{TiO}_{2}$ film whose thickness was reduced in the etching process. The described method was used to obtain strip waveguides of the rib width $w$ and height $t$. The width $w$ of the ribs of the produced strip waveguides was from 1 to $10 \mu \mathrm{m}$, and the height $t$ was $6 \mathrm{~nm}$.

Strip waveguides were produced through selective etching of films $\mathrm{SiO}_{2}: \mathrm{TiO}_{2}$. To achieve the above, we applied $40 \%$ water solution of ammonia fluoride $\left(\mathrm{NH}_{4} \mathrm{~F}\right)$. The composition of the solution was as follows: $200 \mathrm{ml}$ of water $\left(\mathrm{H}_{2} \mathrm{O}\right)+20 \mathrm{ml}$ of $40 \%$ solution of ammonia fluoride $\left(\mathrm{NH}_{4} \mathrm{~F}\right)+10 \mathrm{ml}$ of $80 \%$ acetic acid $\left(\mathrm{CH}_{3} \mathrm{COOH}\right)$. Etching depth was determined by measuring each time with an ellipsometer (SENTECH SE400) the thickness of $\mathrm{SiO}_{2}: \mathrm{TiO}_{2}$ film before and after etching. The etching processes were carried out in the solution temperature of $30{ }^{\circ} \mathrm{C}$. By approximating the experimental 


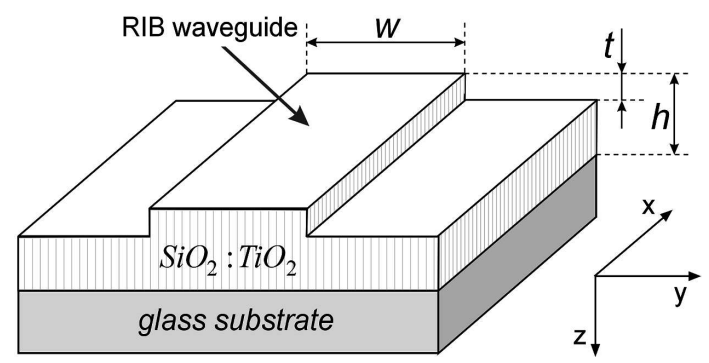

Fig. 1. Diagram of rib waveguide.

runs with linear relations the rates of etching were determined. The etching rate has been determined as $(0.23 \pm 0.01) \mathrm{nm} / \mathrm{s}$. Technological characteristics for other solutions and $\mathrm{SiO}_{2}: \mathrm{TiO}_{2}$ films annealed in lower temperature were presented in Ref. [13].

\section{Theoretical analysis}

In the experimental part of the paper, the results for the wavelength $\lambda=635 \mathrm{~nm}$ will be presented. In this part of the work the results of theoretical analysis are presented. Figure 2 presents the calculated modal characteristics of a slab waveguide. In the calculations for the wavelength $\lambda=635 \mathrm{~nm}$ the following refractive indexes have been used: substrate $n_{\mathrm{b}}=1.515$, waveguide film $n_{1}=1.793$ and cover $n_{\mathrm{c}}=1.000$. The slab waveguide is a single mode in the film thickness range from $d=0.092 \mu \mathrm{m}$ to $0.424 \mu \mathrm{m}$.

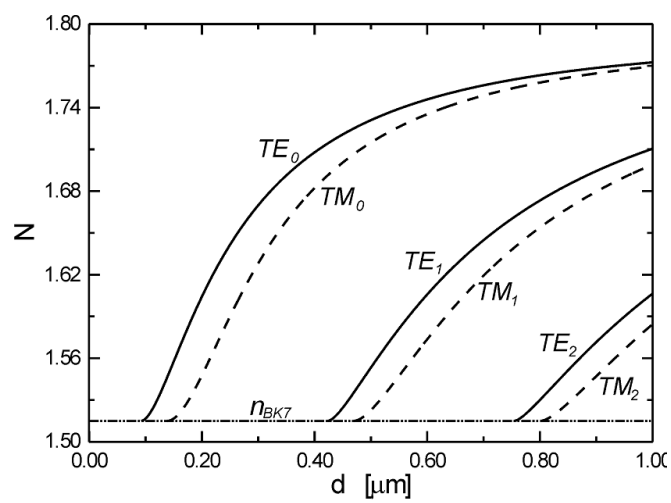

Fig. 2. Modal characteristics of slab waveguide. $\lambda=635 \mathrm{~nm}$.

Modal characteristics of the RIB waveguides are presented in Fig. 3. The calculations were carried out using a simple effective index method (EIM) according to the following scheme [14]:

$$
\begin{aligned}
& N\left(E_{r, s}^{y}\right)=\left\{\mathrm{TE}_{s-1}\left(\begin{array}{c}
n_{\mathrm{c}} \\
\frac{\overline{n_{1}}}{n_{\mathrm{b}}}
\end{array}\right),\right. \\
& \left.\operatorname{TM}_{r-1}(N(d=h-t)|N(d=h)| N(d=h-t))\right\}(1)
\end{aligned}
$$

It can be seen from the presented relations that the width $w$ of the rib corresponding to the mode cut-off $E_{2,1}^{y}$ strongly depends on the height $t$ of the rib. The bigger is the rib height $t$ the lower is the cut-off width $w_{\text {cut }}$. Accordingly, larger rib heights $t$ correspond to higher differences of the extreme values of effective refractive indexes $N_{\text {max }}-N_{\text {min }}$.

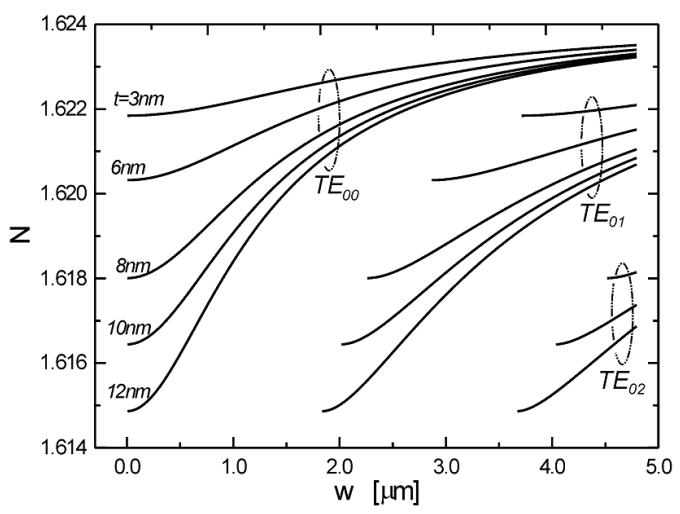

Fig. 3. Modal characteristics of rib waveguides. $h=$ $225 \mathrm{~nm}, \lambda=635 \mathrm{~nm}$.

\section{Measurement setup}

For the produced strip waveguides the power distribution in the near field was recorded. The measurement setup is presented in Fig. 4. The laser diode (LD) was applied in the research as light source of the wavelength $\lambda=635 \mathrm{~nm}$. Strip waveguides were excited with single mode fibre (SMF) of the cut-off wavelength $\lambda_{\text {cut }}=590 \mathrm{~nm}$. The controlled coupling of waveguide fibre with strip waveguides was made possible using a precise shift system $x y z$. The distribution of power in the near field was recorded with a CCD camera coupled with a computer.

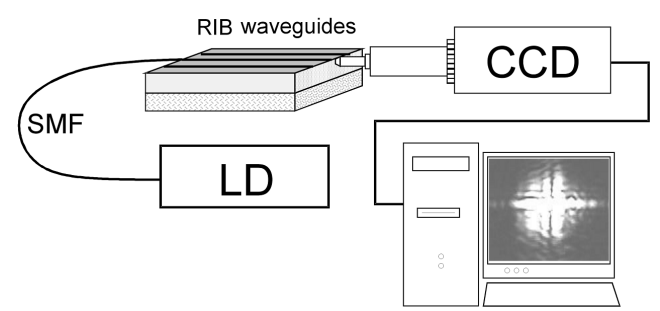

Fig. 4. Measurement setup.LD - laser diode, CCD CCD camera, SMF - single mode optical fiber.

\section{Experimental results}

In the measurement setup presented in Fig. 4 the distributions of power in the near field were recorded for the produced strip waveguides. The investigation involved strip waveguides of rib height $t=5 \mathrm{~nm}$. In all cases the power distribution for different excitation condition was recorded, i.e., by changing slightly the position of the fiber with respect to the strip waveguide. The 
simplest power distribution, insensitive to the change of the coupling conditions fiber-strip waveguide, shows that the strip waveguide is of single-mode character. The recorded power distributions for the waveguide of rib width $w=2 \div 5 \mu \mathrm{m}$, are presented in Fig. 5 . These results were obtained for rib waveguides of the length $24 \mathrm{~mm}$.

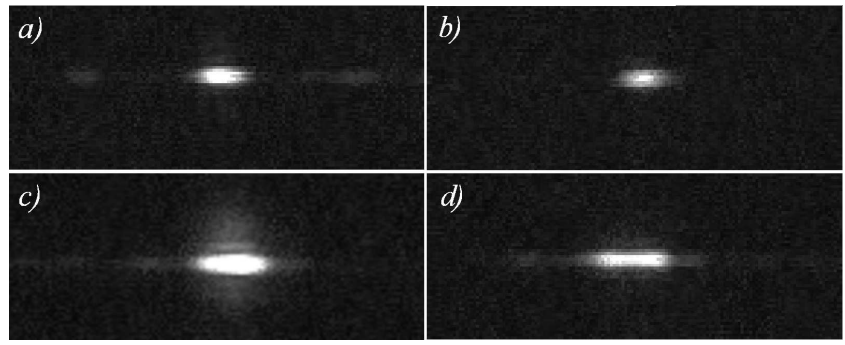

Fig. 5. Power distributions in near field of rib waveguides for different rib width (a) $w=2 \mu \mathrm{m}$, (b) $w=$ $3 \mu \mathrm{m},(\mathrm{c}) w=4 \mu \mathrm{m},(\mathrm{d}) w=5 \mu \mathrm{m}$.

Power distributions for the rib width $w<4 \mu \mathrm{m}$ (Figs. 5a,b) are the simplest possible and insensitive to the changes of excitation conditions, which proves that the waveguides are of single-mode character. It could have been expected basing on the calculation results presented in Fig. 3. The distributions of power for the strip waveguides of rib width $w>3 \mu \mathrm{m}$ have a complex character, which proves that they are multi-mode waveguides.

The investigated waveguides were characterized by low attenuation and their excitation was not difficult. The obtained results show that strip waveguides obtained with the application of the presented method can be applied in integrated optical systems.

\section{Summary}

The method of chemical etching of $\mathrm{SiO}_{2}: \mathrm{TiO}_{2}$ films presented in this work allows in a relatively simple way fabrication of strip waveguides from the films obtained with the sol-gel method. Such waveguides, having high refractive index, applied in planar sensor system with phase detection will allow us to obtain high measurement sensitivity. The presented fabrication method of strip waveguides is being developed. The main objective of the carried out investigations is the optimization of technological process involving the production of low-loss single-mode strip waveguides of high refractive indexes. The mentioned waveguides will be applied in planar chemical and biochemical waveguides working in the system of the Mach-Zehnder interferometer or the Young interferometer.

\section{Acknowledgments}

This work was partially financed from the research grant of the NCBiR R01 0034 06/2009.

\section{References}

[1] A. Opilski, R. Rogoziński, M. Błahut, P. Karasiński, K. Gut, Z. Opilski, Opt. Eng. 36, 1625 (1997).

[2] M. Błahut, D.Kasprzak, Acta Phys. Pol. A 116, 261 (2009).

[3] K. Wörhoff, A. Dreissen, P.V. Lambeck, L.T.H. Hilderink, P.W.C. Linders, T.J.A. Popma, Sens. Actuators. A 74, 9 (1999).

[4] C.J. Brinker, G.W. Scherer, Sol-gel Science, Academic Press, San Diego 1990.

[5] W. Lukosz, Sens. Actuators B 29, 37 (1995).

[6] J. Vörös, J.J. Ramsden, G. Csúcs, I. Szendrö, S.M. De Paul, M. Textor, N.D. Spencer, Biomaterials 23, 3699 (2003).

[7] P. Karasiński, Opt. Appl. 34, 467 (2004).

[8] P. Karasiński, Opt. Appl. 33, 477 (2003).

[9] M. Blahut, D. Kasprzak, Acta Phys. Pol. A 116, 261 (2009).

[10] C. Tyszkiewicz, A. Szpakowski, T. Pustelny, Acta Phys. Pol. A 116, 419 (2009).

[11] P. Karasiński, Opt. Appl. 19, 13 (2011).

[12] P. Karasiński, Opto-Electron. Rev. 18, 146 (2010).

[13] P. Karasiński, R. Rogoziński, Opt. Commun. 245 237 (2005).

[14] K.S. Chiang, Proc. SPIE 2399, 2 (1995). 